\title{
The Effect of Novel Rhenium Compounds on Lymphosarcoma, PC-3 Prostate and Myeloid Leukemia Cancer Cell Lines and an Investigation on the DNA Binding Properties of One of these Compounds through Electronic Spectroscopy
}

\section{Carl Parson ${ }^{1}$, Valerie Smith ${ }^{1}$, Christopher Krauss ${ }^{1}$, Hirendra N Banerjee ${ }^{1 \star}$, Christopher Reilly ${ }^{2}$, Jeanette A Krause ${ }^{3}$, James M Wachira ${ }^{4}$,} Dipak Giri ${ }^{5}$, Angela Winstead ${ }^{5}$ and Santosh K Mandal ${ }^{5 *}$

${ }^{1}$ Department of Biology and Pharmaceutical Sciences, Elizabeth City State University-University of North Carolina, Elizabeth City, NC 27909, USA

${ }^{2}$ Department of Biomedical Sciences and Pathobiology, Virginia-Maryland Regional College of Veterinary Medicine, Virginia Polytechnic Institute and State University,

Blacksburg, Virginia 24061, USA

${ }^{3}$ Department of Chemistry, University of Cincinnati, Cincinnati, OH 45221, USA

${ }^{4}$ Department of Biology, Morgan State University, Baltimore, MD 21251, USA

${ }^{5}$ Department of Chemistry, Morgan State University, Baltimore, MD 21251, USA

\begin{abstract}
Despite the tremendous success of cisplatin and other platinum-based anticancer drugs, severe toxicity and resistance to tumors limit their applications. It is believed that the coordination of the metal to DNA bases causes the ruptures of the cancer as well as normal cells. A search for anticancer drugs with different modes of action resulted in the synthesis of variety of novel compounds. Recently we synthesized a series of novel rhenium pentylcarbonato compounds (PC1-PC6). The rhenium atom in each compound is coordinated to a planar heterocyclic aromatic ligand, thereby forcing each compound to intercalate between the DNA bases. The UV absorption titrations of PC6 with DNA shows hypochromic effect with concomitant bathochromic shift of the charge transfer band at $290 \mathrm{~nm}$. These results suggest that the compound PC6 binds to DNA through intercalation. It is likely that many of the other PC-series of compounds will behave in a similar manner. We have observed that the PC-series of compounds are strong cytotoxic agents against lymphosarcoma (average $\mathrm{GI} 50 \approx 2.3 \pm .6 \mu \mathrm{M}$ ), PC-3 prostate (average GI50 $\approx 2.8 \pm 0.6 \mu \mathrm{M}$ ) and myeloid leukemia (average $\mathrm{GI} 50 \approx 3.0 \pm .6 \mu \mathrm{M}$ ) cancer cell lines. The average $\mathrm{GI} 50$ values of the $\mathrm{PC}$-series of compounds are much less than the corresponding GI50 values of cisplatin. Also each of the PC-series of compounds exhibits less toxicity than cisplatin in the glomerular mesangial cells.
\end{abstract}

Keywords: Rhenium Compounds; Lymphosarcoma; PC-3 Prostate; Myeloid Leukemia; Cancer Cells; Mesangial Cells; DNA Binding; Electronic Spectroscopy; Hypochromic Effect; Bathochromic Shift

\section{Abbreviations}

GI50: Concentration required to have 50\% cell-growth inhibition

\section{Introduction}

The serendipitous discovery of the anticancer property of cisplatin [1] contributed to the development of cancer chemotherapy. Due to its severe side effects and resistance to tumor, clinical effectiveness of cisplatin is limited. Second and third generation platinum drugs are not free from side effects and spontaneous or acquired resistance. As a result, it has been proposed that we should move away from the 'platinum paradigm' by developing drugs based on other metals which have different mechanisms of action [2,3]. Non-platinum complexes such as those of ruthenium [4], titanium [5], gold [6], tin [7], palladium [8], rhodium [9], bismuth [10], and gallium [11] exhibit very strong cytotoxicity and possess distinct chemical advantages over cisplatin and related drugs. In fact, some of them entered clinical trials. This opens the door for the exploration of non-platinum anticancer drugs.

Rhenium organometallics are another very new class of promising antiproliferative compounds. For example, several tricarbonylrhenium compounds have been found to be cytotoxic against numerous cancer cell lines [12-15]. In the present study, we synthesized six novel rhenium pentylcarbanato compounds PC1-PC6 [16]. The structure of each compound is depicted in Figure 1. Unlike the rhenium compounds noted above [12-15], the PC-series of compounds exhibit fluorescence [16]. Here we report the cytotoxic effects of the compounds PC1-PC6 on lymphosarcoma, PC-3 prostate, and myeloid leukemia cancer cells and mesangial cells and the DNA-binding study of the compound PC6 using electronic spectroscopy (UV-Visible spectrophotometric titrations).

\section{Materials and Methods:}

$\operatorname{Re}_{2}(\mathrm{CO})_{10}$ and the polypyridyls were obtained from commercial sources. Tris buffer was prepared according to standard protocol: 5 mM Tris-HCl, $50 \mathrm{mM} \mathrm{NaCl}, \mathrm{pH}$ 7.2. Calf thymus DNA (CT-DNA) was purchased from Sigma-Aldrich. Solution of CT-DNA in Tris buffer gave a ratio of UV absorbance $\left(\mathrm{A}_{260} / \mathrm{A}_{280}\right)$ of $\approx 1.9$ at 260 and 280

*Corresponding author: Hirendra N Banerjee, Department of Biology and Pharmaceutical Sciences, Elizabeth City State University-University of North Carolina, 1704 Weeksville Road, Elizabeth City, NC 27909, USA, Tel: 252335 3241; Email: bhirendranath@mail.ecsu.edu

Santosh K Mandal, Department of Chemistry, Morgan State University, 1700 East Cold Spring Lane, Baltimore, MD 21251, USA; E-mail: santosh.mandal@morgan.edu

Received October 25, 2013; Accepted December 18, 2013; Published December 27, 2013

Citation: Parson C, Smith V, Krauss C, Banerjee HN, Reilly C, et al. (2013) The Effect of Novel Rhenium Compounds on Lymphosarcoma, PC-3 Prostate and Myeloid Leukemia Cancer Cell Lines and an Investigation on the DNA Binding Properties of One of these Compounds through Electronic Spectroscopy. J Bioprocess Biotech 4: 141 doi: 10.4172/2155-9821.1000141

Copyright: $\odot 2013$ Parson C, et al. This is an open-access article distributed under the terms of the Creative Commons Attribution License, which permits unrestricted use, distribution, and reproduction in any medium, provided the original author and source are credited. 
Citation: Parson C, Smith V, Krauss C, Banerjee HN, Reilly C, et al. (2013) The Effect of Novel Rhenium Compounds on Lymphosarcoma, PC-3 Prostate and Myeloid Leukemia Cancer Cell Lines and an Investigation on the DNA Binding Properties of One of these Compounds through Electronic Spectroscopy. J Bioprocess Biotech 4: 141 doi: 10.4172/2155-9821.1000141

Page 2 of 5
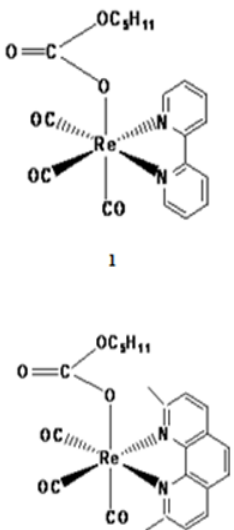

4
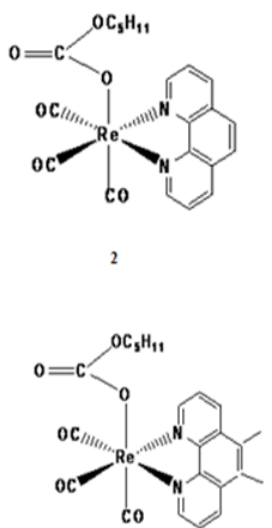
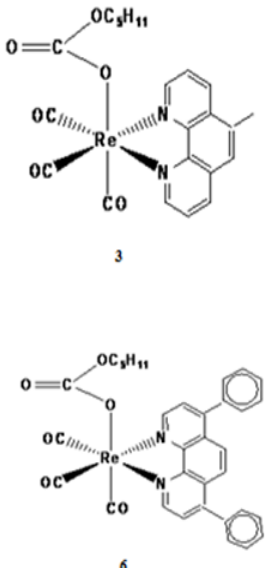

Figure 1: The structural formulae of the PC-series of compounds PC1-PC6.

$\mathrm{nm}$, indicating that the DNA was sufficiently free of protein [17]. The concentration of CT- DNA in nucleotide phosphate was determined spectrophotometrically using a molar absorptivity of $6600 \mathrm{M}^{-1} \mathrm{~cm}^{-1}(260$ $\mathrm{nm}$ ) [18]. The UV-visible spectra were recorded at room temperature using a Varian Cary 50 Scan UV-Visible Spectrophotometer.

\section{Cell Culture}

Lymphosarcoma and myeloid leukemia cancer cell lines were obtained from Coriel Institute, MD(USA) and cultured in RPMI 1640 medium supplemented with $10 \%$ Fetal Bovine Serum, penicillin and streptomycin antibiotics, grown at $37^{\circ} \mathrm{C}$ in a $\mathrm{CO}_{2}$ incubator. $\mathrm{PC}-3$ prostate cancer cell lines were obtained from ATCC, VA (USA) and cultured in the same growth conditions stated above. Mouse glomerular mesangial cells were donated by Dr. C. Reilly at Virginia Tech University, VA (USA). The culture conditions were same as above.

\section{Synthesis of rhenium pentylcarbanato compounds (PC1- PC6)}

The rhenium compounds PC1-PC6 were synthesized according to the published procedure [16]. In brief, a mixture of $\operatorname{Re}_{2}(\mathrm{CO})_{10}$ and the corresponding polypyridyls in 1:2 mole ratio was refluxed in 1-pentanol while $\mathrm{CO}_{2}$ was bubbled through the solutions. The polypyridyls in compounds PC1-PC6 are 2,2'-bipyridyl, 1,10-phenanthroline (phen), 5-methyl-1,10-phenanthroline, 2,9-dimethyl-1,10-phenanthroline (neocuproin), 5,6-dimethyl-1,10-phenanthroline, and 4,7-diphenyl1,10-phenanthroline (bathophenanthroline), respectively. The reaction was discontinued after 36 hours. After cooling to room temperature, the solids PC1-PC6 were isolated by filtration.

\section{UV Absorption Titrations}

We selected only compound PC6 for UV absorption titrations. The titrations of PC6 in Tris buffer were carried out using a fixed concentration $(20 \mu \mathrm{M})$ of PC6 to which DNA solutions were added. Initially, $3000 \mu \mathrm{L}$ of the blank buffer and $3000 \mu \mathrm{L}$ solution of PC6 (20 $\mu \mathrm{M})$ were placed in the reference and sample cuvettes, respectively. The first spectrum was recorded in the range of 235-700 nm. During the titrations, a measured amount of DNA was added to each cuvette from the DNA stock solution so that the final concentration of the DNA becomes $10,20,30,40,50$, and $60 \mu \mathrm{M}$. The solutions were mixed thoroughly by repeated inversion and were allowed to incubate for 10 minutes before the absorption spectra were recorded. The change in concentration of the compound PC6 due to each titration was negligible.

\section{Cytotoxicity Assay}

The cancer cell lines were grown in 96-well plates to confluency, the cells were then kept in serum-free medium overnight and then treated with different doses of drugs PC1-PC6 (dissolved in DMSO) along with untreated cells and DMSO vehicular control for 48 hours. DMSO was used as vehicular control, non-drug treated as negative control and cisplatin as positive control. A Trypan blue assay was done to measure cell viability using a standard hemocytometer and light microscope.

\section{Statistical Analysis}

Each experiment was repeated three times and statistical $t$ test was used to analyze the results with $\mathrm{P}<0.05$.

\section{Results and Discussion}

As shown in Figures 1-4, the rhenium atom in each of the PC-series of compounds is octahedrally coordinated to a chelated (bidentate) polypyridyl ligand, three adjacent $\mathrm{CO}$ molecules, and a pentylcarbonate group $\left[-\mathrm{OC}(\mathrm{O}) \mathrm{OC}_{5} \mathrm{H}_{11}\right]$ in a facial $(\mathrm{fac})$ arrangement. For example, the rhenium atom in PC1 is octahedrally coordinated to chelated 2,2'-bipyridyl ligand, three adjacent CO's, and a pentylcarbonate group. Likewise, the rhenium atom in PC4 is octahedrally coordinated to chelated neocuproin, three adjacent CO's and a pentylcarbonate group and the rhenium atom in PC6 is octahedrally coordinated to chelated bathophenanthroline, three adjacent CO's and a pentylcarbonate group. The PC-series of compounds were characterized spectroscopically. Additionally, PC1, PC4 and PC6 were characterized through X-ray crystallography. The X-ray structures of PC1, PC4, and PC6 are shown in Figures 2-4, respectively. The phenanthroline ring in PC4 is not totally planar (see Figure 5 and Table 1 ) with a $0.1166 \AA$ deviation from planarity (deviation of $6.4^{\circ}$ and $7.6^{\circ}$ between the 3 rings). The crystal structures of PC1 and PC6 were published earlier [16]. A complete crystallographic data for PC4 will be published elsewhere.

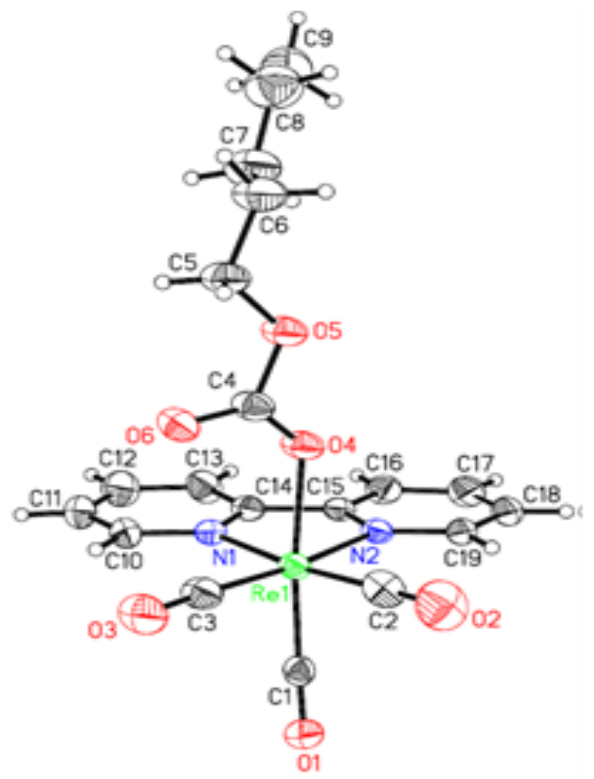

Figure 2: X-ray structure of PC1. (courtesy: Elsevier). 
Citation: Parson C, Smith V, Krauss C, Banerjee HN, Reilly C, et al. (2013) The Effect of Novel Rhenium Compounds on Lymphosarcoma, PC-3 Prostate and Myeloid Leukemia Cancer Cell Lines and an Investigation on the DNA Binding Properties of One of these Compounds through Electronic Spectroscopy. J Bioprocess Biotech 4: 141 doi: 10.4172/2155-9821.1000141

Page 3 of 5

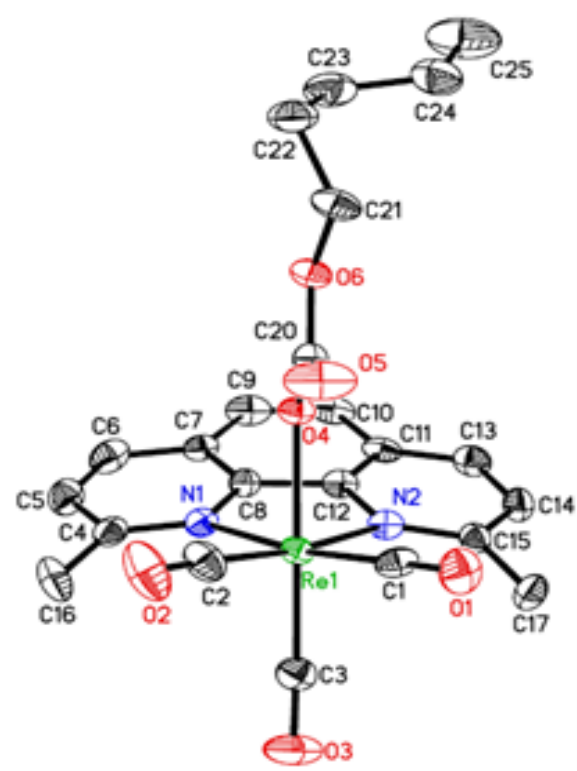

Figure 3: X-ray structure of PC4.

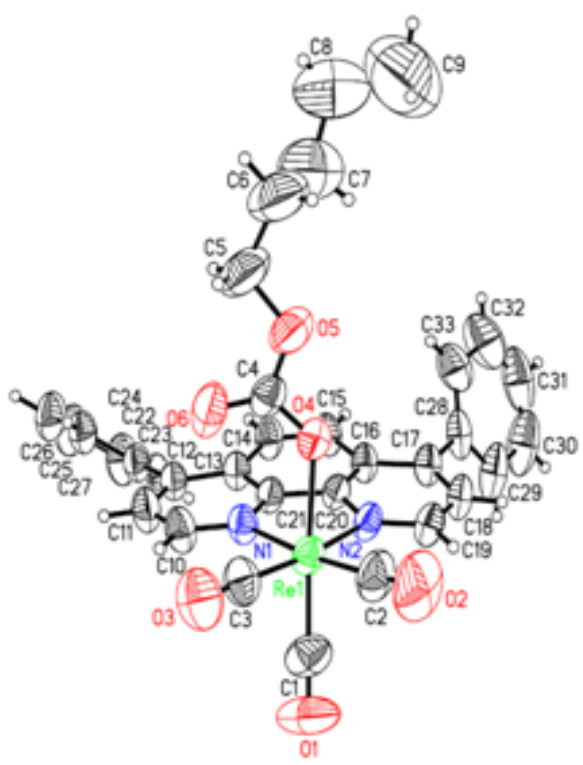

Figure 4: X-ray structure of PC6. (courtesy: Elsevier)

DNA binding studies are important because many anticancer agents work through binding to DNA causing DNA damage in cancer cells, interrupting replication and transcription processes, and inducing apoptosis. The electronic spectroscopy is the most common technique to find out the interaction of compounds with DNA [19]. When a compound binds to DNA through intercalation, the UV-Visible spectra usually shows hypochromism with a red shift. Each of the PC1-PC6 compounds is coordinated to a planar aromatic heterocyclic ligand (see, Figures 1-5). It is therefore possible that each compound will bind to DNA in an intercalative mode, involving a stacking interaction between the aromatic chromophores and DNA base pairs. Figure 6 depicts the UV-Visible spectra of the compound PC6 $(20 \mu \mathrm{M}$ in Tris buffer) in the absence and presence of calf thymus DNA. The intensity of the charge transfer band at $290 \mathrm{~nm}$ in PC6 decreases as the DNA concentration (range of 10-60 $\mu \mathrm{M}$ ) increases. A small red shift of the band at $290 \mathrm{~nm}$ is observed concomitantly after each addition of DNA. A red shift to $295 \mathrm{~nm}$ is observed when $60 \mu \mathrm{M}$ of DNA was added to fixed concentration $(20 \mu \mathrm{M})$ of PC6. Based on the UV-visible spectra of the compound PC6, it may be concluded that PC6 binds to DNA in an intercalative fashion. Our conclusion may be corroborated by the fact that the phenanthroline rings are planar or near planar (see Figure 5) which facilitate their insertion into the DNA base pairs. Thus PC6 and may be other PC compounds PC2-PC5 except PC1 do not bind to DNA via covalent interaction through nitrogen bases (adenine, cytosine, guanine and thymine). PC1 might not follow intercalation mechanism because of the presence of nonintercalative 2,2-bipyridyl ligand. Cisplatin and other platinum metal drugs directly bind (form covalent bond through nitrogen bases of DNA) to the DNA. As a result normal cells are highly affected resulting in severe toxic side effects. It is therefore possible that many of the the PC-series of compounds might not exhibit severe side effects. It is worth mentioning that analogous rhenium compounds exhibited very negligible toxicity towards fibroblasts [15]. We have not extensively studied the mechanism of action using other techniques and with other PC-series of compounds. Therefore it is not impossible that the PC compounds will follow other modes of action too. 1, 10-phenanthroline (phen) is an intercalative ligand. It is expected that metal-phen complexes will follow intercalation mechanism. In fact, Barton group [20] proposed a major groove intercalation and a minor groove surface-bound interaction for the binding of $\left[\mathrm{Ru}(\text { phen })_{3}\right]^{2+}$ to DNA from equilibrium dialysis and photophysical methods. However, Satyanarayana, et. al. $[21,22]$ from viscosity measurements and Errikson, et. al. [23, 24] from

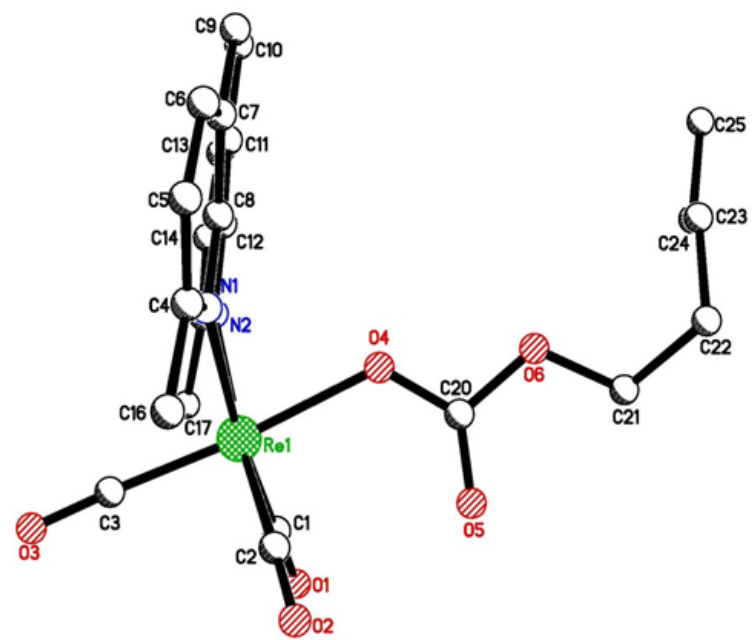

Figure 5: X-ray structure of PC4 showing a nearly planar phenanthroline ring

\begin{tabular}{|c|c|c|}
\hline Least Square Planes & Deviation $(\mathbf{A})$ from Planarity & Dihedral Angle ( $\left.{ }^{\circ}\right)$ \\
\hline N1-C4-C5-C6-C7-C8 & 0.0155 & $6.4(2)$ \\
\hline C7-C8-C9-C10-C11-C12 & 0.0262 & $7.6(2)$ \\
\hline N2-C11-C12-C13-C14-C15 & 0.0206 & \\
\hline N1- N2- Re1 & 0 & \\
\hline N1-N2-C4 thru C15 & 0.1166 & $19.7(1)$ \\
\hline O4-O5-O6-C20-C21 & 0.0331 & $83.0(2)$ \\
\hline C22-C23-C24-C25 & 0.0568 & $75.7(6)$ \\
\hline
\end{tabular}

Table 1: The least square planes and their deviations from planarity and dihedral angles for PC4. 
Citation: Parson C, Smith V, Krauss C, Banerjee HN, Reilly C, et al. (2013) The Effect of Novel Rhenium Compounds on Lymphosarcoma, PC-3 Prostate and Myeloid Leukemia Cancer Cell Lines and an Investigation on the DNA Binding Properties of One of these Compounds through Electronic Spectroscopy. J Bioprocess Biotech 4: 141 doi: 10.4172/2155-9821.1000141

Page 4 of 5

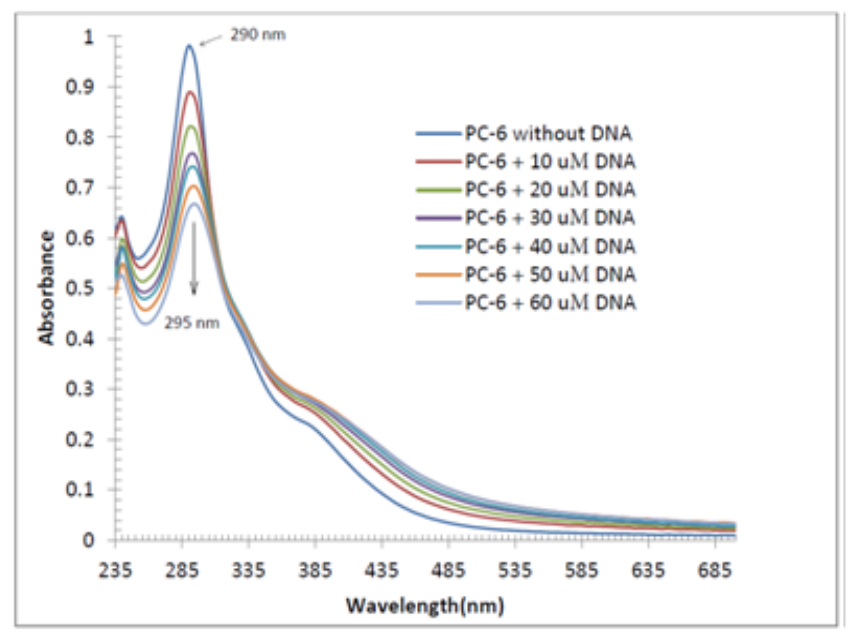

Figure 6: Electronic absorption spectra for the titration of $20 \mu \mathrm{M}$ of compound PC6 in the absence and presence of varied amount of DNA.

NMR and CD spectra indicated no intercalative binding. We chose to study the DNA binding properties of PC6 because the planar aromatic heterocyclic ligand in PC6 has two additional planar aromatic (phenyl) rings which might facilitate PC6 to follow intercalaive mode of action. Although our prediction is right, the presence of planar aromatic ring is not the final arbiter of intercalation mechanism. For example, the mode of action of the complex $\left[\mathrm{Ru}(\mathrm{bpy})_{2}(\mathrm{dppn})\right] \mathrm{Cl}_{2}$ (where, dppn $=$ benzo[i]dipyrido[3,2-a:2',3'-c]phenazine) seems to involve interactions with cell membranes, rather than interactions with DNA (in this case intercalation of the dppn ligand was anticipated) [25].

To determine the inhibitory potency of active compounds (GI50, $50 \%$ cell-growth inhibition), tests were extended for compounds PC1PC6 to varying concentrations for different cancer cell lines. Most of the six drugs showed GI 50 around 3-4 $\mu \mathrm{M}$ (Table 2). Interestingly, the Re drugs (PC 1-PC6) showed less toxicity than cisplatin in the glomerular mesangial cells. Because nephrotoxicity is a major problem in cisplatin treatment, the titled Re compounds could be an ideal alternative. Significantly, all the Re compounds (PC 1-PC6) showed efficacy against all the cancer cells treated at a lower dose than the cisplatin.

\section{Acknowledgments}

Partially supported by US-NIH-RISE, US-National Science Foundation LSAMP institutional support Award to Elizabeth City State University, NC, TMCF-DOE award to Dr.H.Banerjee and the work at MSU was partially supported by grants from the National Institutes of Health (Grant No. G11HD038439) and Nuclear Regulatory Commission (Grant No. NRC-HQ-12-G-27-0086). Crystallographic data were collected through the SCrALS (Service Crystallography at Advanced Light Source) program at Beamline 11.3.1 at the Advanced Light Source (ALS), Lawrence Berkeley National Laboratory. The ALS is supported by the U.S. Department of Energy, Office of Energy Sciences Materials Sciences Division, under contract DE-AC02-05CH11231.

\section{References}

1. Rosenberg B, Vancamp L, Krigas T (1965) Inhibition of Cell Division in Escherichia Coli by Electrolysis Products From a Platinum Electrode. Nature 205: 698-699.

2. Dyson PJ, Sava G (2006) Metal-Based Antitumour Drugs in the Post Genomic Era. Dalton Trans 16: 1929-1933.

3. Fricker SP (2007) Metal Based Drugs: From Serendipity to Design. Dalton Trans 43: 4903-4917.

4. Guidi F, Modesti A, Landini I, Nobili S, Mini E, Et. Al., (2013) The Molecular

\begin{tabular}{|c|c|c|c|c|}
\hline Compounds & Lymphosarcoma & $\begin{array}{c}\text { PC-3 Prostate } \\
\text { Cancer Cells }\end{array}$ & $\begin{array}{c}\text { Myeloid Leukemia } \\
\text { Cancer Cells }\end{array}$ & $\begin{array}{c}\text { Mesangial } \\
\text { Cells }\end{array}$ \\
\hline PC1 & $3 . \pm .5$ & $4 \pm .5$ & $4 \pm .9$ & $15 \pm .8$ \\
\hline PC2 & $2 . \pm .6$ & $2 \pm .7$ & $3 \pm .5$ & $13 \pm .5$ \\
\hline PC3 & $2 \pm .7$ & $4 \pm .5$ & $3 \pm .6$ & $12 \pm .5$ \\
\hline PC4 & $3 \pm .6$ & $2 \pm .8$ & $2 \pm .5$ & $14 \pm .5$ \\
\hline PC5 & $2 \pm .8$ & $3 \pm .7$ & $4 \pm .7$ & $11 \pm .6$ \\
\hline PC6 & $2 \pm .5$ & $2 \pm .6$ & $2 \pm .5$ & $13 \pm .8$ \\
\hline Cisplatin & $6 \pm .5$ & $8 \pm .5$ & $10 \pm .7$ & $4 \pm .4$ \\
\hline DMSO & NA & NA & NA & NA \\
\hline
\end{tabular}

GI50 (mean \pm S.D.) refers to the concentration required to have $50 \%$ cell-growth inhibition; (-) indicates that the isolated is inactive (negative at 100 or GI50>100 $\mu \mathrm{M})$; N/A: no data available

Table 2: The effects of the PC-series of compounds (PC1-PC6) on lyphosarcoma, $\mathrm{PC}-3$ prostate, and myeloid leukemia cancer cells and mesangial cells.

Mechanisms of Antimetastatic Ruthenium Compounds Explored through Dige Proteomics. J Inorg Biochem 118: 94-99.

5. Caruso F, Rossi M (2004) Antitumor Titanium Compounds. Mini-Rev Med Chem 4: 49-60.

6. Ott I (2009) On The Medicinal Chemistry of Gold Complexes as Anticancer Drugs. Coord Chem Rev 253: 1670-1681.

7. Hadjikakou SK, Hadjiliadis N (2009) Anti-Proliferative and Anti-Tumor Activity of Organotin Compounds. Coord Chem Rev 253: 235-249.

8. Reedijk J (2009) Platinum Anticancer Coordination Compounds: Study of DNA Binding Inspires New Drug Design. Eur J Inorg Chem 10: 1303-1312.

9. Leung C-H, Zhong H-J, Chan Ds-H, Ma D-L (2013) Bioactive Iridium and Rhodium Complexes As Therapeutic Agents. Coord Chem Rev 257: 1764-1776.

10. Tiekink Ert (2002) Antimony and Bismuth Compounds in Oncology. Crit Rev Oncol Hemat 42: 217-224.

11. Jakupec MA, Keppler BK (2004) Gallium in Cancer Treatment. Curr Top Med Chem 4: 1575-1583.

12. Yan Y-K, Cho Se, Shaffer KA, Rowell Je, Barnes Bj, et. al., (2000) Cytotoxicity of Rhenium(I) Alkoxo and Hydroxo Carbonyl Complexes in Murine and Human Tumor Cells. Pharmazie 55: 307-313.

13. Wang W, Yan YK, Hor TSA, Vittal JJ, Wheaton Jr, et.al., (2002) Synthesis, X-Ray Structures and Cytotoxicity of Rhenium(I) Carbonyl 2-(Dimethylamino) Ethoxide Complexes. Polyhedron 21: 1991-1999.

14. Zhang J, Vittal JJ, Henderson W, Wheaton Jr, Hall IH, et. al., (2002) Tricarbonylrhenium(I) Complexes of Phosphine-Derivatized Amines, Amino Acids and a Model Peptide: Structures, Solution Behavior And Cytotoxicity. J Organomet Chem 650: 123-132

15. Ho J, Lee WY, Koh KJT, Lee PPF, Yan YK (2013) Rhenium(I) Tricarbony Complexes of Salicylaldehyde Semicarbazones: Synthesis, Crystal Structures and Cytotoxicity. J Inorg Biochem 119: 10-20.

16. Mbagu Mk, Kebulu D, Winstead A, Pramanik Sk, Banerjee Hn, et. al., (2012) Fac-Tricarbonyl (Pentylcarbonato) (a-Diimine) Rhenium Complexes: One-Pot Synthesis, Characterization, Fluorescence Studies, And Cytotoxic Activity Against Human Mda-Mb-231 Breast, Ccl-227 Colon And Bxpc-3 Pancreatic Carcinoma Cell Lines. Inorg Chem Comm 21: 35-38.

17. Marmur J (1961) A Procedure for the Isolation of Deoxyribonucleic Acid from Micro-Organisms. J Mol Biol 3: 208-218.

18. Reichmann ME, Rice SA, Thomas CA, Doty PJ (1954) A Further Examination of the Molecular Weight and Size of Desoxypentose Nucleic Acid. J Am Chem Soc 76: 3047-3053.

19. Barton JK, Danishefsky A, Goldberg J (1984) Tris(Phenanthroline)Ruthenium(II) Stereoselectivity in Binding Dna. J Am Chem Soc 106: 2172-2176.

20. Barton JK, Goldberg JM, Kumer CV, Turro NJ (1986) Binding Modes and Base Specificity of Tris(phenanthroline)ruthenium(II) Enantiomers with Nucleic Acids: Tuning the Stereoselectivity. J Am Chem Soc 108: 2081-2088.

21. Satyanarayana S, Dabrowiak JC, Chaires JB (1992) Neither Delta- nor Lambdatris(phenanthroline)ruthenium(II) binds to DNA by classical intercalation. Biochemistry 31: 9319-9324. 
Citation: Parson C, Smith V, Krauss C, Banerjee HN, Reilly C, et al. (2013) The Effect of Novel Rhenium Compounds on Lymphosarcoma, PC-3 Prostate and Myeloid Leukemia Cancer Cell Lines and an Investigation on the DNA Binding Properties of One of these Compounds through Electronic Spectroscopy. J Bioprocess Biotech 4: 141 doi: 10.4172/2155-9821.1000141

Page 5 of 5

22. Satyanarayana S, Dabrowiak JC, Chaires JB (1993) Tris(phenanthroline) ruthenium(II) enantiomer interactions with DNA: Mode and specificity of binding. Biochemistry 32: 2573-2584.

23. Eriksson M, Leijon M, Hiort C, Norden B, Graeslund A (1992) Minor groove binding of $[\mathrm{Ru}(\mathrm{phen}) 3] 2+$ to [d(CGCGATCGCG)]2 evidenced by twodimensional NMR. J Am Chem Soc 114: 4933-4934.
24. Eriksson M, Leijon M, Hiort C, Norden B, Graeslund A (1994) Binding of Delta- and Lambda-[Ru(phen)3]2+ to [d(CGCGATCGCG)]2 Studied by NMR. Biochemistry 33: 5031-5040.

25. Schatzschneider U, Niesel J, Ott I, Gust R, Alborzinia H, et. al., (2008) Cellular Uptake, Cytotoxicity and Metabolic Profiling of Human Cancer Cells Treated with Ruthenium(II) Polypyridyl Complexes $[\mathrm{Ru}(\mathrm{Bpy}) 2(\mathrm{~N}-\mathrm{N})] \mathrm{Cl} 2$ With N-$\mathrm{N}=$ Bpy, Phen, Dpq, Dppz and Dppn. Chem Med Chem 3: 1104-1109. 